\title{
High lysozyme activity families in Polish black and white cattle
}

\author{
Krzysztof WALAWSKI, Chandra S. PAREEK, \\ Urszula CZARNIK and Tadeusz ZABOLEWICZ
}

\begin{abstract}
Walawski K., Pareek C. S., Czarnik U. and Zabolewicz T. 1999. High lysozyme activity families in Polish black and white cattle. Acta Theriologica 44: 91-100.

Recent achievements in specificity of lysozyme gene organization and expression made it possible to consider lysozyme as a candidate gene for natural resistance in cattle. In our research affort on more than 10000 animals reared in large herds were examined. Obtained results were the background for determining genetic basis of lysozyme activity differentiation. The aim of present investigation was to trace out high lysozyme activity $\left(\mathrm{LZM}^{+}\right)$animals. This was achieved by pre-selecting animals on the basis of quantitative analysis of lysozyme activity measurements and verification by single gene allelic segregation. Generally, a very low frequency of $\mathrm{LZM}^{+}$ carriers were identified in a random sampling population. However two sires and some dams were recognized as $\mathrm{LZM}^{+}$heterozygote. Independent to sex, age and other conditions, the progeny groups alternatively inherited very high or normal lysozyme activity were stated. The obtained results were applied in the experimental breeding program to gain information on the relationship between lysozyme polymorphism and natural resistance specificity in cattle.
\end{abstract}

University of Agriculture and Technology, Department of Animal Genetics, Oczapowskiego 5, 10-718 Olsztyn, Poland

Key words: cattle, lysozyme activity, pedigree analysis

\section{Introduction}

Lysozyme (EC 3.2.1.17) is one of the most important factor of natural resistance. Antibacterial enzymatic function of lysozyme is generally well recognized. The explanation of its anti-viral and anti-neoplastic activity is currently in the subject of intensive research. Taking into the account its generally well known as well as possible multi-side protective functions, all cases of lysozyme genetic variability should be inquired by considering lysozyme as potential genetic marker of natural resistance processes. Such types of genetic variability is observed in cattle. On the population scale, it is expressed by very high lysozyme activity in some animals (Lie 1980). One incidence of such alternatively inherited very high or normal lysozyme activity was described (Lie and Solbu 1983, Olsaker et al. 1993).

Macrophage (PMN) expressed $3.5 \mathrm{~kb}$ cDNA-insert lysozyme encoding gene was localized in chromosome 5q23 (Brunner et al. 1994), the same chromosomal region 
where cluster of bovine lysozyme gene family assigned (Irwin et al. 1984, Gallagher et al. 1993). Sequence analysis of immuno-relevant lysozyme encoding region (Steinhoff et al. 1994, Henke et al. 1996) made it possible to recognize microsatellite (Lys-mic) polymorphism (Weikard et al. 1996). A total of 12 Lys-mic variants were observed in different bovine breeds and species. In Polish black-and-white cattle 5 Lys-mic gene variants were observed, with one exceptional Lys-mic variant being responsible for high lysozyme activity (Pareek et al. 1998). This new Lys-mic variant has shown absolute conformity in relation to its phenotypically recognized $\mathrm{LZM}^{+}$single gene effect.

During 1985-1997 more than 10000 animals were routinely tested in our laboratory. Obtained results were used as a background for detection of genetic and non-genetic factors influencing blood serum and milk lysozyme variability (Walawski et al. 1993, Walawski and Czarnik 1995). In this presented report, we are attempting to evaluate $\mathrm{LZM}^{+}$gene carriers in Polish black-and-white cattle population.

\section{Material and methods}

A selected groups of AI elite sires, young bulls from testing station, as well as cows and progenies at different ages reared in several cattle herds were measured for blood serum lysozyme activity using modified turbidimetric method of Metzger (1970). The repeatability coefficients $(R$ values) were estimated by correlation analysis of repeated measurements sampling from the same animals. A mixed model procedure for variance analysis was applied:

$\mathrm{Y}_{\mathrm{ijkl}}=\mu+\mathrm{G}_{\mathrm{i}}+\mathrm{T}_{\mathrm{ij}}+\mathrm{I}_{\mathrm{ijk}}+\mathrm{e}_{\mathrm{ijk} \mathbf{l}}$,

$\mathrm{Y}_{\mathrm{ijkl}}=$ lysozyme activity of the progeny,

$\mu=$ average mean,

$\mathrm{G}_{\mathrm{i}}$ effect of $\mathrm{i}^{\text {th }}$ LZM group,

$\mathrm{T}_{\mathrm{ij}}=$ effect of $\mathrm{j}^{\text {th }}$ sampling term,

$I_{i j k}=$ interaction effect of $i^{\text {th }}$ and $j^{\text {th }}$ groups,

$\mathrm{e}_{\mathrm{ijk} \mathrm{k}}=$ residual error,

High lysozyme activity animals $\left(\mathrm{LZM}^{+}\right.$) were pre-selected on the basis of bi-model distribution (Lie and Solbu 1983). Next, the individuals having been qualified in successive sampling term as plus-variant group were considered as a potential $\mathrm{LZM}^{+}$individuals based on double standard deviation superiority $(\mu \pm 2 \mathrm{SD})$. Finally, genotype of potential $\mathrm{LZM}^{+}$carriers were verified by parent and progeny analysis.

\section{Results}

Characteristic measurements of lysozyme activity in examined Polish black and white cattle population are presented in Table 1. Obtained results indicate that group of adult AI sires can be distinguished by higher lysozyme activity, in comparison to cows, young breeding bulls, heifers and calves (differences highly significants at $p<0.01$ ). Extraordinary wide range of phenotypic variation in lysozyme measurements was observed in all groups: of sires (3.2-46.0 U), cows $(0.8-72.0 \mathrm{U})$, heifers $(1.8-48.3 \mathrm{U})$ and calves (2.6-34.1 U). The repeatability of 
lysozyme measurments are different in analyzed groups. In AI sire group $R$ value is negative and low $(R=-0.14)$, while in the groups of cows $(R=0.28-0.37)$, young bulls $(R=0.40)$, heifers $(R=0.41)$ and calves $(R=0.37)$ are positive and statistically highly significant.

Generally the frequency of $\mathrm{LZM}^{+}$carriers was low in the randomly examined population. Thus, in the group of $66 \mathrm{AI}$ sires no $\mathrm{LZM}^{+}$carriers were observed whereas, by examining 107 young bulls only one case was disclosed. One herd of cows was distinguished itself by a relatively high frequency of $\mathrm{LZM}^{+}(7 \%)$, but in case of other herds (Table 1) the $\mathrm{LZM}^{+}$carriers were detected with very low frequencies $(0-2 \%)$. Additional results (Tables 2 and 3 ) showed that the occurrence of $\mathrm{LZM}^{+}$carriers is the basic pre-requisite factor in differentiating $R$ values in examined cattle groups. Simultaneous approach depending on comparative analysis of $\mathrm{LZM}^{+}$and $\mathrm{LZM}^{0}$ group of cows apart from one large group was effected by its generally low, statistically non-significant, irregular, positive and negative relations of $R$ values. This illustrate a non-genetic fluctuation of lysozyme activity in both $\mathrm{LZM}^{+}$and $\mathrm{LZM}^{0}$ groups. The same tendency of low $\mathrm{R}$ value in the groups of independently analyzed LZM ${ }^{+}$and $\mathrm{LZM}^{0}$ animals was observed in the remaining examined cows and young cattle herds. This result is in full accordance with Mao et al. (1992) who reported that a high decrease of lysozyme level heritability coefficient $\left(h^{2}\right)$ was caused by simulated elimination of $\mathrm{LZM}^{+}$animals from examined herds. Very high estimates of $R$ value or $h^{2}$ found in the common population in comparison to its very low estimates in separately analyzed groups of $\mathrm{LZM}^{+}$and $\mathrm{LZM}^{0}$ animals indicate that the $\mathrm{LZM}^{+} / \mathrm{LZM}^{0}$ allelic effect is exclusively one statistically verified genetic factor differentiating lysozyme activity in cattle blood serum.

Obtained results show limited penetration of $\mathrm{LZM}^{+}$gene in the individual animal dispersed in several herds. In all cases being presented in Table $1 \mathrm{LZM}^{+}$ cows were not qualified for the selected group of bulls mothers, and its influence

Table 1. Variability and repeatability of blood serum lysozyme activity in different breeding groups. $R$ - repeatability coefficient, $n / \mathrm{LZM}^{+}$- number of $\mathrm{LZM}^{+}$carriers.

\begin{tabular}{|c|c|c|c|c|c|}
\hline \multirow{2}{*}{ Group } & \multirow{2}{*}{ Methodical approach } & \multicolumn{2}{|c|}{ Lysozyme (U) } & \multirow{2}{*}{$R$} & \multirow{2}{*}{$n / \mathrm{LZM}^{+}$} \\
\hline & & Mean & $\mathrm{SD}$ & & \\
\hline Bulls ( $3-10$ years) & AI station, $n=66,3$ repeats & 17.6 & 9.3 & -0.14 & - \\
\hline Bulls (6-12 months) & Testing station, $n=107,3$ repeats & 6.0 & 3.7 & +0.40 & 1 \\
\hline $\begin{array}{l}\text { Cows } \\
\text { (lactation } \mathrm{I}+\mathrm{II}+\mathrm{III})\end{array}$ & $\begin{array}{l}\text { Herd C, } n=82,9 \text { repeats } \\
(3+3+3) / \text { lactation }\end{array}$ & 8.6 & 3.7 & +0.40 & 5 \\
\hline Cows (lactation I) & Herd B+M., $n=124,5$ repeats & 11.4 & 4.7 & +0.28 & 2 \\
\hline Cows (lactation I) & Herd C, $n=172,3$ repeats & 8.6 & 4.4 & +0.37 & 8 \\
\hline Hiefers (6-15 months) & Herd $\mathrm{C}+\mathrm{Z}, n=128,4$ repeats & 7.1 & 3.7 & +0.41 & 2 \\
\hline Calves ( $1-6$ months) & Herd $\mathrm{C}+\mathrm{Z}+\mathrm{J}, n=188,3$ repeats & 9.6 & 4.7 & +0.37 & 2 \\
\hline
\end{tabular}




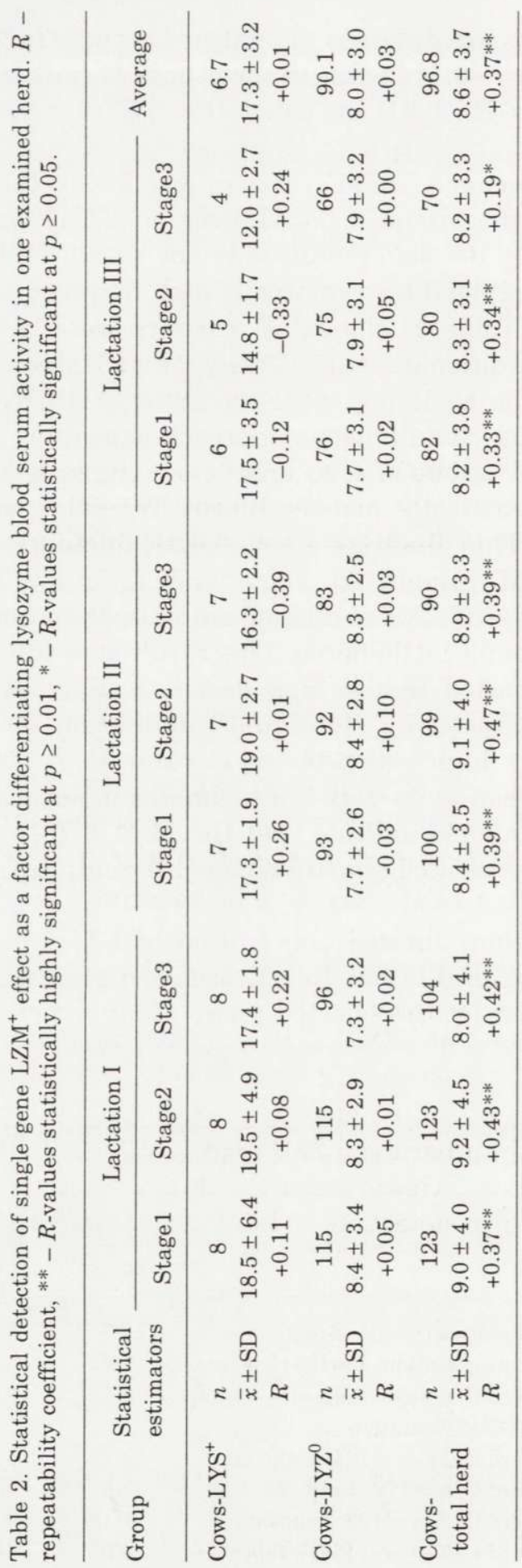


Table 3. Variability and repeatability of blood serum lysozyme activity in the progeny groups of $\mathrm{LZM}^{+}$sires. $R$ - repeatability coefficient, $n / \mathrm{LZM}^{+}-$number of $\mathrm{LZM}^{+}$carriers.

\begin{tabular}{llcccc}
\hline \multirow{2}{*}{ Group } & \multicolumn{1}{c}{ Methodical approach } & \multicolumn{3}{c}{ Lysozyme (U) } \\
\cline { 3 - 6 } & & Mean & SD & $R$ & $n /$ LZM $^{+}$ \\
\hline Calves (1-3 months) & Czort progeny herd, $n=88,2$ repeats & 18.2 & 10.1 & +0.35 & 41 \\
Heifers (6-12 months) & Czort progeny herd, $n=71,3$ repeats & 22.0 & 12.6 & +0.83 & 35 \\
Heifers (12-18 months) & Paran progeny herd, $n=47,3$ repeats & 21.6 & 11.6 & +0.82 & 23 \\
Cows (lactation I) & Paran progeny herd, $n=13,2$ repeats & 23.3 & 11.2 & +0.82 & 6 \\
\hline
\end{tabular}

for genetic structure of breeding population is perceived low. However, in the group of young bulls tested in 6-12 month of age, the case of Czort 09312-4-5 showed statistically verified very high lysozyme activity (Fig. 1). This bull was used for natural mating service in one herd. In two years time, more than 150 heifers were calved and in the follow time Czort 09312-4-5 is designed for mating service with cows having difficulties in calving through artificial insemination.

Pedigree analysis of Czort 09312-4-5 (Fig. 1) indicate that $\mathrm{LZM}^{+}$allele was inherited from mother. Further family group embraced two maternal half brother sires which were used in artificial insemination center. These bulls, namely, Step 08949-4-5 was not tested and Wador 09173-4-8 was characterized by LZM ${ }^{0}$ allele. Three maternal half sisters from which two cows carried $\mathrm{LZM}^{+}$allele were not qualified as bulls mother, but third cow that was mother of two AI bulls unfortunately representing a $\mathrm{LZM}^{0}$ recessive homozygote genotype.

Genotype of Czort 09312-4-5 was attested by five times folding phenotypic measurements for lysozyme activity, in all cases exceeding more than $30 \mathrm{U}$ as well as analysis of 88 progenies obtained in all cases from LZM ${ }^{0}$ mothers which indicate full equilibrium of $\mathrm{LZM}^{+} / \mathrm{LZM}^{0}$ segregation. The male progenies of Czort 09312-4-5 were tested three folds at 1, 3 and 6 months of age and female progenies were additionally tested at 10 month of age. In all sampling terms differences between alternatively inherited $\mathrm{LZM}^{+}$and $\mathrm{LZM}^{0}$ progenies groups were statistically highly significant. However, in the group of calves which were tested at 1 month of age statistical detection of $\mathrm{LZM}^{+}$and $\mathrm{LZM}^{0}$ individuals were difficult and differences of lysozyme activity were little expansive. In these young calves frequency of LZM genotype was documented as: 5 animals with arbitrary LZM ${ }^{+}$ allele (6\%), 18 animals (20\%) with increase but statistically not verified $\mathrm{LZM}^{+}$ activity and 65 animals (74\%) with normal or low LZM activity.Therefore, in young calves, the possibility of $\mathrm{LZM}^{+}$animal detection was generally impended, but in 3,6 and 10 months aged animals, the possibility of such doubtful results were incidentally low (only 1-2 cases with increase but statistically no verified results).

Final classification of $\mathrm{LZM}^{+}$and $\mathrm{LYS}^{0}$ progeny groups (Table 3) were created on the basis of 3 or 4 folder lysozyme activity surveys. The repeatability coefficient 


\section{A. Pedigree chart of Czort 09312-4-5}

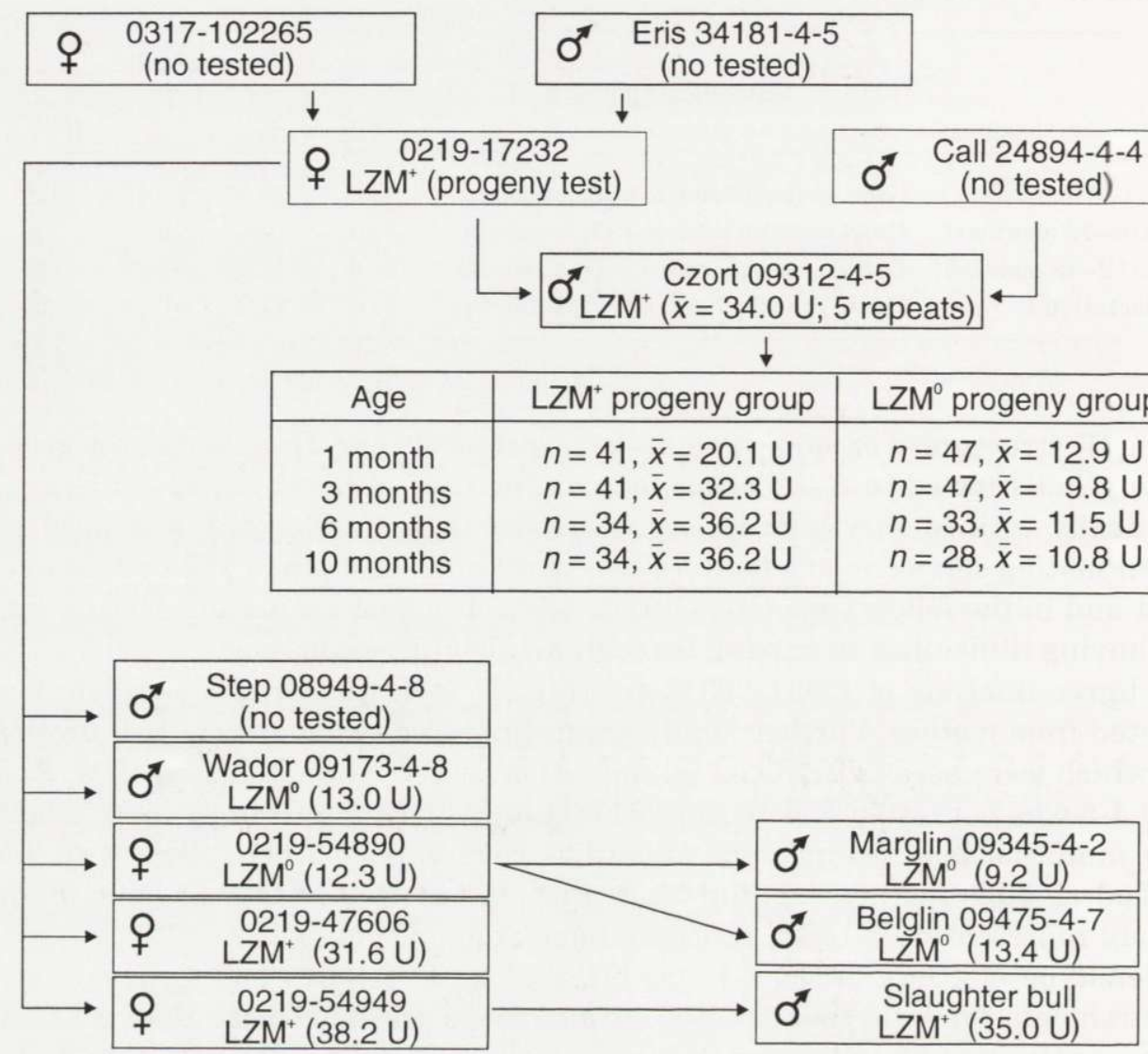

\section{B. Pedigree chart of Paran 51681-1-8}

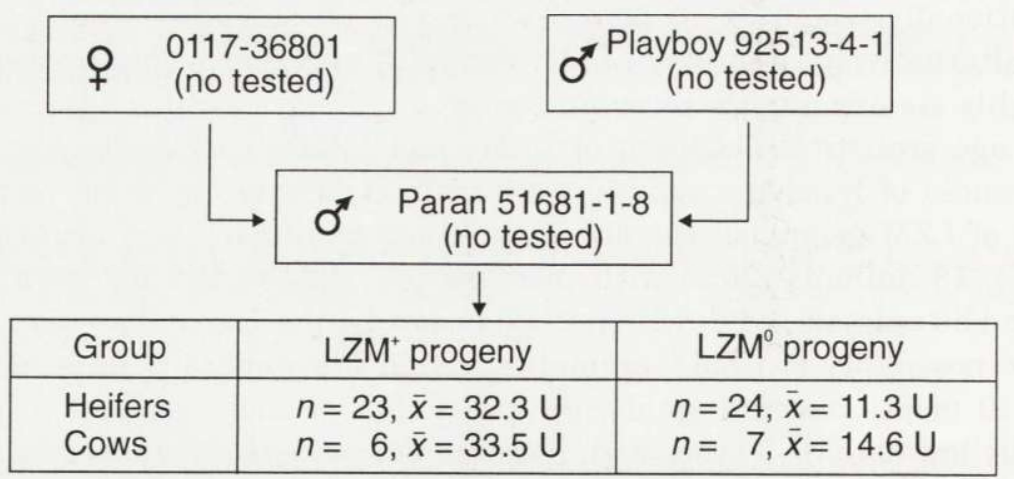

Fig. 1. Pedigree scheme of $\mathrm{LZM}^{+}$sire carriers. 
of several lysozyme activity measurement is relatively low in animal tested in the age of 1 month $(R=0.35)$ and very high $(R=0.83)$ in animal tested in the age of 3,6 and 10 months. Additional analysis made it possible to find out statistical highly significant relationship $(p<0.01)$ between blood serum lysozyme activity in mothers and progenies tested at early post-calving period $(r=+0.39)$, while the same animals tested in elder age no relations between mothers and progenies were noted $(r=$ ca 0.00$)$. This indicate that occurance of possible non-genetic association between cows and new born calves lysozyme activity is transmitted by colostrum.

A second case of $\mathrm{LZM}^{+}$sire family was detected in Paran 51681-1-2. This bull was recognized during comparative analysis of AI elite sires progenies without testing in laboratory survey. Pedigree chart (Fig. 1) indicated that the parental information is incomplete. Paran 51681-1-2 was used in AI station for a very short time. Earlier its mother and half sisters were eliminated from the breeding population, and later no sire progenies were qualified for reproduction. Currently, female progenies of Paran 51681-1-2 are limited with some cows being used for progeny breeding evaluation test, while other cows and heifers are dispersed in several herds. Genotype of Paran 51681-1-2 was established on the basis of progeny analysis. The examined group is comprised of 60 progenies. Triplicate test for lysozyme activity was applied for 47 heifers and duplicate test for 13 cows. The differentiation of lysozyme activity between $\mathrm{LZM}^{+}$and $\mathrm{LZM}^{0}$ progenies groups were statistically highly significant with very high $R$ values $(R=0.82)$ in several measurements.

\section{Discussion}

A comparison of lysozyme activity measurement is difficult for common application of different methods (Klass et al. 1977). Our methodological procedure is based on spectro-photometric quantitative survey of Micrococcus lysodeiticus bacteria subjected to blood serum lytic power. Generally, by anticipating the possible occurrence of different lysozyme variants in cattle, which cannot provide the linear relationship between biological (enzymatic and non-enzymatic) function and lysozyme weight contents, therefore, procedure with no numerical transformation based on hen egg or other lysozyme standard was used. Furthermore, no correct records according to age, season and other factors were introduced for lysozyme activity estimation because, examined individuals and animal groups were appreciated on the basis of several related measurements fluctuating lysozyme activity in different physiological stages.

Application of specific multi-step approach of genotype detection was affected by abnormal phenotypic variation. The individuals distinguished by very high lysozyme activity classified into a separate group. Therefore, it was necessary to 
consider two different phenotypic groups of $\mathrm{LZM}^{+}$and $\mathrm{LZM}^{0}$ animals. Statistical detection of potential $\mathrm{LZM}^{+}$carriers heterozygous in all cases were coordinated with parents or progeny analysis. Genetically non-confirmed very high lysozyme activity cases in bulls (over $45 \mathrm{U}$ ), in cows (over $70 \mathrm{U}$ ) and in young calves (over $35 \mathrm{U}$ ) were detected in separate non-repeated surveys. Our own experience indicate that $2-3$ repeats of statistically verified high activity records connected with gene segregation analysis is necessary in recognition of $\mathrm{LZM}^{+}$carriers.

Recent result brings out a wide prospective in the field of genetic determination of lysozyme activity in cattle. Detection of micro-satellite polymorphism as well as its established connection with hypothetical LZM ${ }^{+}$allele allows to use Lys-mic primers for lysozyme genotyping (Pareek et al. 1998) With this approach, it can be possible to obtain a high lysozyme activity breeding lines or herds. However, an implementation of suitable breeding strategy should be required to recognize biological value of $\mathrm{LZM}^{+}$animals. Further research in this field is necessary to explain of lysozyme gene organization and its expression specificity. Still, the main question in this subject is to find out an alternative approach for the possible relationship between Lys-mic polymorphism and $\mathrm{LZM}^{+}$; is it a transcriptional or structural differentiating effects? Independent to its theoretical consideration, applicability aspects of currently reported results should be verified.

Our results indicate a possible association between lysozyme activity in blood serum in mothers and newborn calves. Lysozyme transmitted through colostrum is an important defense factor for newborn animals (see: Reiter 1985, Lie and Syed 1986). It is known that bovine lysozyme gene encoding for neutrophil and mammary gland tissue specific cDNA libraries are different (Steinhoff et al. 1994, Seyfert et al. 1996). However, all aspects of the relationship between blood serum, colostrum and milk lysozyme specificity are still not well recognized. Further investigations should be emphasized on its biological specificity in colostrum and milk descendent from cows distinguished as $\mathrm{LZM}^{+}$carriers and $\mathrm{LZM}^{0}$ in respect to natural resistance profit in the progenies. Milk composition and its biological specificity in relation to lysozyme differentiation seems to be also interesting in respect to nutritive and technological properties of milk. Blood serum and milk lysozyme activity are characterized by very high repeatability in several lactation and lactation stages (Walawski et al. 1993, Walawski and Czarnik 1995) However, the relation between lysozyme activity in blood serum and milk from healthy cows is generally low. The result of undertaken trails of lysozyme activity is aimed to recognize the relationship between lysozyme activity and blood and milk diagnostic indices (Walawski et al. 1988, 1993) are statistically not reliable in consideration to non-adequate representation of $\mathrm{LZM}^{+}$and $\mathrm{LZM}^{0}$ animal groups in randomly mating population.

The results of currently presented $\mathrm{LZM}^{+}$sires and dams families are already utilized in individual mating service and MOET program which drive to establish suitable large progeny groups for further experimental investigations. 


\section{Conclusions}

1. Obtained results of statistical analyses indicate the occurrence of only one $\mathrm{LZM}^{+}$single gene effect significantly differentiating lysozyme activity variation in blood serum of cattle. Independently of age, season and other conditions highly significant differences between $\mathrm{LZM}^{+}$and $\mathrm{LZM}^{0}$ animal groups were recognized.

2. Randomly examined population of Polish black-and-white cattle is characterized by very low frequency of $\mathrm{LZM}^{+}$animals. Nevertheless, two cases of $\mathrm{LZM}^{+}$ heterozygote sires and some $\mathrm{LZM}^{+}$dams families were detected.

3. Identified $\mathrm{LZM}^{+}$carrier animals should be used for the arrangement of experimental herds by using full correct methodical approach to examine possible relation between lysozyme polymorphism and natural resistance properties in cattle.

Acknowledgements: This work was supported in part by the State Committee for Scientific Research, project no. 5P06D 01908. For the year 1996-97 this work was conducted with bilateral scientific agreement between Research Institute for Farm Animals, Department of Molecular Biology in Dummerstorf (Germany) and University of Agriculture and Technology, Department of Animal Genetics, in Olsztyn (Poland).

We thank Prof Manfred Schwerin and other German scientists as well as Polish animal breeding institutes and nominal breeding farm-managers from Bystrze, Małżewko, Cieszymowo and Nowa Wioska for their prominent aid in hitherto collaboration.

\section{References}

Brunner R. M., Henke M., Guerin G., Goldammer T., Seyfert H.-M. and Schwerin M. 1994. Brief data reports: The macrophage expressed variant of the bovine lysozyme encoding gene maps to chromosome 5q23. Mammalian Genome 5: 834.

Gallagher D. S. Jr, Treadigill D. W., Ryan A. M. and Womack J. E. 1993. Physical mapping of the lysozyme gene family in cattle. Mammalian Genome 4: 368-373.

Henke M., Hobom G., Senft B. and Seyfert H. M. 1996. Structural deviations in a bovine low expression lysozyme-encoding gene active in tissues other than stomach. Gene 178: 131-37.

Irwin D. M., Sidow A., White R. T. and Wilson A. C. 1984. Multiple genes for ruminant lysozymes. Mammalian Genome 3: 73-85.

Klass H. J., Hopkins J., Neale G. and Peters T. J. 1977. The estimation of serum lysozyme: a comparison of four assay methods. Biochemical Medicine 18: 15-57.

Lie O. 1980. Genetic variation in the serum lysozyme activity in cattle. Acta Veterinaria Scandinavica 21: $448-450$.

Lie O. and Solbu H. 1983. Evidence for a major gene regulating serum lysozyme activity in cattle. Zeitschrift für Tierzüchtung und Züchtungsbiologie 100: 143-148.

Lie O. and Syed M. 1986. Some properties of the lysozyme in serum and colostrum from cows with high and low lytic power against Micrococcus lysodeicticus. Animal Genetics 17: 47-59.

Mao I. L., Svandson M. and Solbu H. 1992. Single gene effect on serum lysozyme activity and its association with production, intake somatic cell count in lactating cows. Journal of Dairy Science 75: 146 (In Supplement).

Metzger M. 1970. [Lysozyme]. [In: Practice of immunology. S. Slopek, ed]. Państwowy Zakład Wydawnictw Lekarskich, Warszawa: 181-189. [In Polish] 
Olsaker I., Mejdell C. M., Sorensen A. and Lie O. 1993. High lysozyme activity in a Norwegian bovine family co-segregates with a restriction fragment length polymorphism. Animal Genetics 24: 421-25.

Pareek C. S., Seyfert H. M., Walawski K., Czarnik U., Guiard V., Grupe S. and Schwerin M. 1998. Co-segregation of alleles at a microsatellite locus within the macrophage expressed lysozyme gene and levels of serum lysozyme activity in two half - sib families of Polish Black and White Lowland cattle. Animal Genetics 29: 441-445.

Reiter B. 1985. The biological significance of the non-immunoglobulin protective in milk: lysozyme, lactoferrin, lactoperoxidase. [In: Developments in Dairy Chemistry, vol. 3. P. F. Fox, ed]. Elsevier, London, New York: 281-288.

Seyfert H. M., Henke M., Interthal H., Klussmann H., Koczan D., Natour S., Pusch S. W., Senft B., Steinhoff U. M., Tuckoricz A. and Hobom G. 1996. Defining candidate genes for mastitis resistance in cattle: the role of lactoferrin and lysozyme. Journal of Animal Breeding and Genetics 133: 269-276.

Steinhoff U. M., Senft B. and Seyfert H. M. 1994. Lysozyme encoding bovine cDNAs from neutrophile granulocytes and mammary gland are derived from a different gene than stomach lysozymes. Gene 143: 271-276.

Walawski K. and Czarnik U. 1995. Repeatability of blood and milk diagnostic indices in several lactation of black and white cattle. Roczniki Naukowe Zootechniki 22: 109-118. [In Polish with English summary]

Walawski K., Kaczmarczyk E., Sowiński G., Czarnik U., Zabolewicz T. and Białłowicz E. 1993. Genetic and non-genetic determination of blood and milk indices repeatability in the black and white cows. Archivum Veterinarium Polonicum 33: 156-176.

Walawski K., Sowiński G., Kruk Z., Zabolewicz T. and Bogdan S. 1988. Relation of some blood diagnostic indices for milk productivity and milk composition in black and white cows. Acta Academie Agriculturae ac Technicae Olsteniensis 2: 95-100. [In Polish with English summary]

Weikard R., Henke M., Kuhn C., Barendse W. and Seyfert H. M. 1996. A polymorphic microsatellite within the immunorelevant bovine lysozyme-encoding gene. Animal Genetics 27: 125 .

Received 25 September 1997, accepted 16 October 1998. 